\title{
Contract Form, Wage Flexibility and Employment
}

\author{
By Thomas Lemieux \\ W. Bentley MacLeod \\ DANIEL PARENT *
}

The recent recession has brought again to the forefront of economic policy debates the issue of unemployment during economic downturns. Competitive labor market theory predicts that downturns should have only modest effects on unemployment. A decrease in aggregate demand might lower output and the demand for labor, but this does not necessarily imply higher unemployment. Lower demand for labor leads to lower wages, with the consequence that some individuals might leave the labor market. The remaining workers need only lower their wage demands until suitable employment is found.

The current recession has shown, yet again, that theory and evidence are on a collision course. One hypothesis, going back to Keynes, is that workers lose their jobs because they are unwilling to accept lower wages. Implicit contract theory, beginning with (Costas Azariadis 1975) and (Martin N. Baily 1974), and subsequently (Paul Beaudry and John DiNardo 1991), suggests rigid wages are the consequence of a contract between firms and risk-averse workers. Yet, (Sherwin Rosen 1985) observes that the hypothesis that wages are the result of an optimal risk-sharing contract implies that laid-off workers are no worse off than employed workers, a prediction that is inconsistent with the evidence 1

In this paper we observe that one can

* Lemieux: University of British Columbia and NBER, email: Thomas.Lemieux@ubc.ca, MacLeod: Columbia University, Institute for Advanced Studies and NBER, email: bentley.macleod@columbia.edu (corresponding author). Parent: HEC Montreal, email: parent.daniel@hec.ca. MacLeod gratefully acknowledges the Russell Sage Foundation and the Leon Levy Foundation for the support of this research.

${ }^{1}$ (Andrew E. Clark 2003) finds a large negative impact of unemployment on subjective well-being, while (Daniel Sullivan and Till von Wachter 2009) find that job loss is associated with significantly higher mortality. build a very simple labor contracting model to explain these facts using three ingredients, two of which pre-date implicit contract theory. The first is the existence of relationship specific investment that both (Gary Becker 1962) and (Jacob Mincer 1962) emphasized as central to the wage setting process.

The second ingredient is contract law for which the protection of specific investments, or what legal scholars call the "reliance interest" (see (L. L. Fuller and William R., Jr. Perdue 1936)) is a central goal of contract enforcement. In particular, if a worker makes an investment, such as moving to take up a job or acquiring some job-specific skills, an employer cannot after the fact unilaterally reduce wages. Legal doctrines, such as good faith and fair dealing, explicitly limit the scope of firms to reduce wages. ${ }^{2}$ When employment contracts cannot be enforced, and firms can unilaterally lower wages, this leads to what (Victor P. Goldberg 1977) calls "holdup", and can lead to an inefficiently low level of reliance by both the worker and the firm.

The final ingredient is asymmetric information. (Oliver D. Hart and John Moore 1988) have shown that when there is symmetric information, and contracts are incomplete, then rational parties would always renegotiate inefficient agreements, leading to efficient employment ex post, which in turn leads to inefficient investment ex ante. (W. Bentley MacLeod and James M. Malcomson 1993) apply these ideas to the employment contract and show that the optimal contract entails fixed wages that are renegotiated in the face of better market alternatives for the worker or the firm. Con-

\footnotetext{
${ }^{2}$ In Rigby v Ferodo [1988] ICR 29, [1987] IRLR 516 the U.K. courts ruled that employers could not unilaterally lower wages.
} 
tracts can be designed to achieve efficiency in a wide variety of cases, including the case of cooperative investment - one party's investment affecting both parties' payoff. Such a model, like implicit contract theory, cannot by itself explain inefficient unemployment ((Oliver D. Hart 1983) explicitly makes the point that asymmetric information is central to a theory of unemployment). Following (Robert E. Hall and Edward P. Lazear 1984), we suppose that there is asymmetric information makes it impossible for firms to efficiently modify wages $e x$ post. Here, we combine asymmetric information regarding worker productivity with relationship-specific investments to produce a simple model where wages are set in advance (consistent with (David Card 1986) who finds that wages are rigid in the short run), and leads to lower employment than the first best.

We also show that although the measurement of worker productivity is costly, inefficient unemployment linked to fixed wages can be reduced by introducing bonus pay. (W. Bentley MacLeod and Daniel Parent 1999) find that the incidence of bonus pay varies with features of the job aside from worker productivity. Comparing bonus-pay and fixed-wage jobs yields a number of important predictions about wages and employment. First, bonus-pay workers are more likely to be employed than workers on fixed-wage jobs. Second, demand shocks should have a larger impact on wages and a smaller impact on employment for bonuspay workers. We find empirical support for both predictions.

\section{Does Contract Form Matter for Employment and Wages?}

Consider a two-period model that illustrates the consequences of specific investment, enforceable wage contracts and asymmetric information, the details of which are found in the appendix. The timing of choices is as follows:

1) In period 1 the worker can accept a wage offer $w^{1}$ from firm $A$ or $B$ and then make a specific investment $k^{1}$ - in order to avoid hold-up the firms agrees not to lower the wage in period 2. Firm A pays a monitoring cost $c$ to produce a publicly observable signal $s \in\{0,1\}$ that is positively correlated with firm productivity. Firm A agrees to pay a bonus $b$ if $s=1$.

2) If the worker rejects both offers, then she waits until the firms realize their productivities, and make new wage offers based upon their realized productivities. She can take up either offer a cost $k^{2}>k^{1}$.

3) If she accepts the offer from say $A$, then in period 2 firm $B$ can offer a new wage $w^{2}$ based on its productivity that she can choose to accept at a cost $k^{2}$.

4) Before production begins, firms can choose to layoff workers. Since firm productivity is private information, workers will refuse to renegotiate wages down in the event the firm has low productivity. Such behavior is a necessary ingredient of any wage contract consummated in period 1.

Suppose that ex ante the worker is better matched at $A$. This model illustrates in the most simple form the trade-off between early investment into firm $A$, against the option value of delaying investment if it turns out that either firm $B$ or exit from the labor market is ex post optimal. Notice that asymmetric information is a key ingredient here. If worker productivity is information that is private to the firm, then workers would never agree to wage cuts because the firm may simply be misrepresenting their costs. Wages can only respond to credible signals, such as a wage offer from another firm 3

The model generates a number of empirical implications discussed in the appendix on how contract forms matters for wages and employment. Most importantly, we expect employment to be higher and less responsive to demand shocks in bonus-pay jobs since fixed-wage workers get laid off whenever productivity falls below $w^{1}$. The pres-

\footnotetext{
${ }^{3}$ See (H. Lorne Carmichael and W. Bentley MacLeod 2003) for a discussion of the credibility of such behavior when contracts are not legally enforceable.
} 
ence of bonus makes the wage rate (inclusive of bonus) more sensitive to demand shocks than under fixed wages, and hence the worker faces a lower probability of layoff under bonus pay.

We explore these implications using data from the Panel Study of Income Dynamics (PSID). In (Thomas Lemieux, W. Bentley MacLeod and Daniel Parent 2009) we show how to exploit the longitudinal nature of the PSID to assign workers to either bonus-pay or fixed-wage jobs. We define a bonus-pay job as a match between a worker and an employer that involves some bonus payments, including commissions and piece rates. Our analysis is based on a 1976-98 sample of male heads of households, where the hourly wage rate is obtained by dividing total labor earnings from all jobs by total hours of work. Given our focus on bonus pay, this wage measure based on total yearly earnings, inclusive of bonus pay, is preferable to "point-in-time" age measures that would likely miss infrequent performance-related payments such as bonuses. Our final sample has 26,146 observations for 3,053 workers, 834 of which are "switchers" observed on both fixed-wage and bonus-pay jobs. This allows us to estimate models with workerspecific fixed effects. More details about the data are provided in (Lemieux, MacLeod and Parent 2009).

We estimate regression equations for wages (annual earnings inclusive of bonuses over annual hours), annual hours of work, and annual earnings. Note that since annual hours are the product of annual weeks and average hours per week, they capture adjustments at both the extensive and intensive margins. The results are likely driven by variation at the extensive margin (probability of employment in a given week) in our sample of male heads of households who tend to work full time when employed.

Consider the (log) wage equation equation for worker $i$ at time $t$ :

$$
\begin{aligned}
& w_{i t}=\alpha+\delta D_{i t}+x_{i t} \beta+ \\
& \gamma^{f}\left(1-D_{i t}\right) u_{i t}+\gamma^{b} D_{i t} u_{i t}+\lambda_{i}+\varepsilon_{i t},
\end{aligned}
$$

where $D_{i t}$ is an indicator variable for bonus pay jobs $\left(D_{i t}=1\right.$ if the worker is in a bonus pay, and zero otherwise); $x_{i t}$ represents standard observable characteristics such as potential experience, education, occupation; $\lambda_{i}$ is an unobservable ability component; $u_{i t}$ is a demand shock that we capture empirically using the county unemployment rate; and $\varepsilon_{i t}$ is an idiosyncratic error term. Note that, as a matter of notational convention, we use the superscript $b$ for bonus-pay jobs, and $f$ for fixed-wage jobs. We also estimate similar equations for hours of work and annual earnings. The parameters of interest are the coefficients on the bonus pay dummy $(\delta)$ reported in Table 1, and the coefficients on the demand shocks $\left(\gamma^{b}\right.$ and $\left.\gamma^{f}\right)$ reported in Table 2 .

As a benchmark, observe that if the market is perfectly competitive, workers are risk averse and monitoring costs are orthogonal to the intrinsic utility of a job, then a worker should be indifferent between the fixed wage in one job, and a compensation package at a job with bonus pay. Moreover, under U.S. law, performance-pay contracts are enforceable under the doctrine of good faith and fair dealing - namely a firm cannot renege upon a bonus pay commitment by firing a worker. Moreover, (James M Malcomson and Frans Spinnewyn 1988) and (Yoshi Kanemoto and W. Bentley MacLeod 1992) show that in a competitive market that efficient agency contracts can be implemented with a sequence of competitive performance-pay contracts. Hence, a priori the there should be no systematic differences between bonus-pay and fixed-wage jobs. We find that this is strongly rejected in the data (see below).

The OLS estimate of bonus pay on wages (Column 1 of Table 1) is positive and significant, but turns insignificant once fixed effects are included in Panel B. This is consistent with the evidence in (Lemieux, MacLeod and Parent 2009) that bonus pay is more prevalent in high value jobs. Adding fixed effects controls for this source of heterogeneity, and the fixed effects estimates are consistent with competitive pricing of worker services - bonus pay jobs do not pay a premium over fixed wage jobs. Notice that bonus pay does make compensation more 


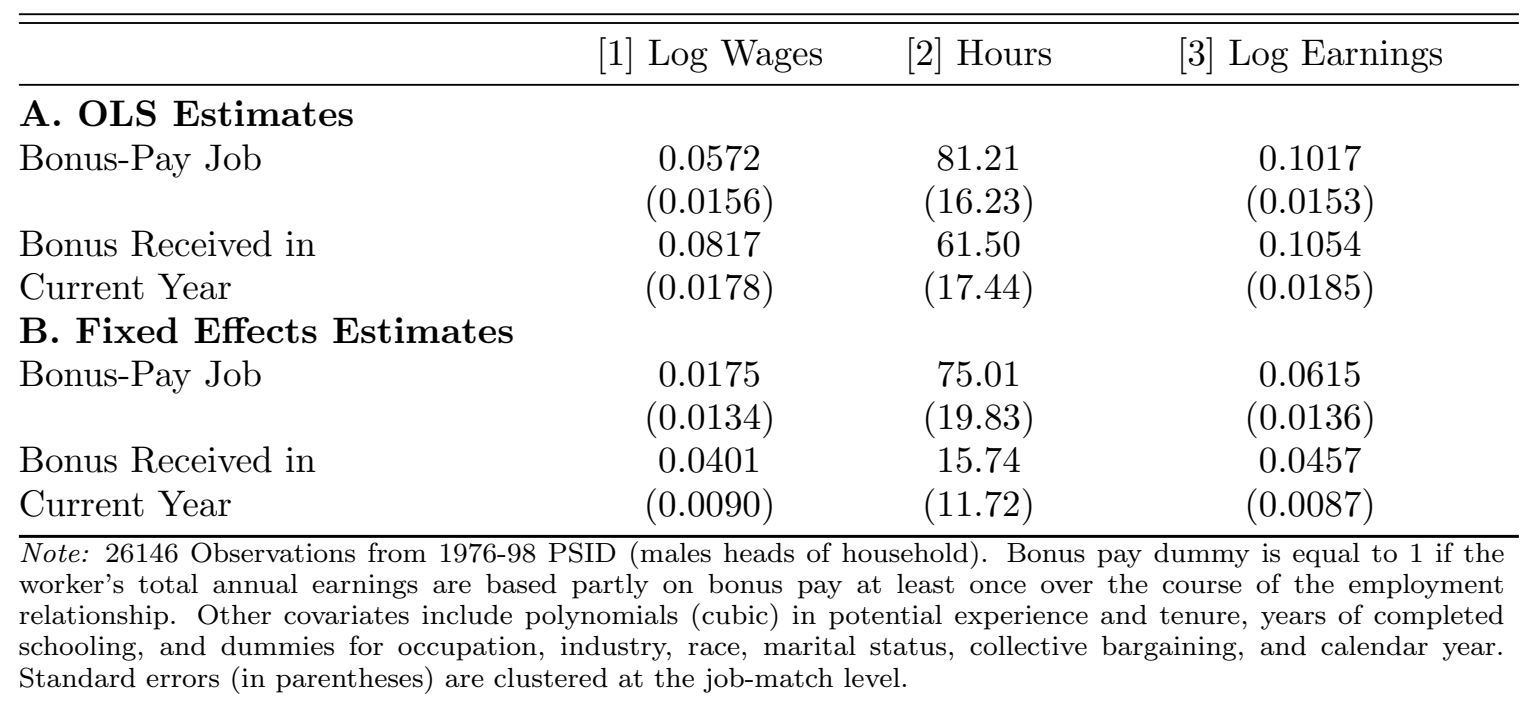

variable, because in the year a bonus is paid, there is a positive effect upon wages.

Column 2 shows that, as expected, workers on bonus pay jobs are more likely to be employed (higher annual hours) even after controlling for fixed effects. Interestingly, the effect of receiving a bonus in the current year has no effect on hours once fixed effects are controlled for. This is not consistent with the predictions of a standard competitive model where bonus payment increases the marginal cost of a work, which in turn should reduce hours. Finally, bonus pay workers tend to have higher annual earnings because they are more likely to be employed. The finding that bonus-pay workers have higher employment is consistent with idiosyncratic shocks to firm productivity that are more likely to result in layoffs for fixed-wage workers.

Consider now the impact of the demand shock $u_{i t}$ affecting all firms. By definition, wages do not respond to demand shocks under fixed wage contracts implying $\gamma^{f}=0$. Since the probability of observing a positive signal $(\mathrm{s}=1)$ increases under a positive demand shock, it also follows that $\gamma^{b}<0$ (an increase in unemployment is a negative demand shock). The results reported in column 1 of Table 2 are consistent with both of these predictions. While, in theory, de- mand shocks should have no effect on wages in fixed-wage jobs, there are a number of reasons why the effect should still be negative, though smaller than in bonus-pay jobs. First some bonus-pay jobs are likely misclassified as fixed-wage jobs ((Lemieux, MacLeod and Parent 2009)). Second, if there is any common information between the worker and the firm, then they could agree to a decrease in fixed wages. It is, therefore, remarkable that the estimate of $\gamma^{f}$ is not significantly different from zero, a result that is certainly inconsistent with standard models of wage formation.

Turning to hours of work, Table 2 shows that an increase in the local unemployment rate has a negative and significant effect for fixed-wage jobs, but no significant effect for bonus-pay jobs. This finding is not consistent with the prediction of implicit contract theory that employment can be set efficiently even when wages do not reflect the worker's marginal product. In contrast, the combination of asymmetric information and firm specific investment predicts a negative effect of a demand shock on employment in fixed wages jobs, and a small effect in bonus pay jobs, which is what we find in column 2 of Table 2.

In column 3 we report the effect of demand shocks on earnings. If workers were fully in- 
Table 2-The Effect of Local Labor Market Conditions

\begin{tabular}{lccc}
\hline \hline & {$[1]$ Log Wages } & {$[2]$ Hours } & {$[3]$} \\
\hline \hline County Uneg Earnings \\
Fixed-Wage Job & -0.0021 & -10.73 & -0.0076 \\
\hline County Unem. Rate X & $(0.0016)$ & $(2.62)$ & $(0.0019)$ \\
Bonus-Pay Job & -0.0072 & 1.22 & -0.0078 \\
\hline p-Value of Test of Equality & $(0.0021)$ & $(3.15)$ & $(0.0017)$ \\
\hline
\end{tabular}

Note: Estimates come from unrestricted regressions in which all covariates are interacted with the performance pay job dummy. See the note to Table 1 for more detail about the sample and other covariates included in the regression models. Standard errors are clustered at the county X year level.

sured there should be no effect, yet we find a strong negative effect. We also find that the magnitude of the effect is the same in both types of jobs, suggesting that ex ante workers can expect similar patterns in future earnings, consistent with the hypothesis of a competitive labor market.

\section{Conclusion}

In this paper, we use data from the Panel Study of Income Dynamics to study the impact of local labor market shocks on wages, hours of work and employment under different contractual arrangements (bonus-pay vs. fixed-wage jobs). Using the county unemployment rate as a proxy for local labor market shocks, we find that wages are quite flexible in bonus-pay jobs, but there is little evidence of flexible wage renegotiation in jobs that do not use bonus pay. Precisely the opposite happens in the case of hours of work.

These results, as well as related findings on differences in the level of wages, hours, and earnings under the two types of contracts, are consistent with two uncontroversial hypotheses - productivity is expensive to measure and employment entails relationshipspecific investments. By contrast, conventional models with risk-sharing contracts are not consistent with these findings since employment should be efficiently allocated (and not respond excessively to demand shocks) even when the wage is fixed for risk-sharing reasons.

The hypothesis that variable compensa- tion can improve employment goes back at least to (M. L. Weitzman 1983)'s work that emphasizes the importance of unforeseen events in the theory of unemployment. In his model variable pay takes the form of profit sharing. Recently, (Omar Azfar and Stephan Danninger 2001) has shown that in the US profit sharing leads to higher employment and more investment into training. (Paul Oyer and Scott Schaefer 2005) extend this point to employment contracts that include stock options. In this paper we focus upon individual, as opposed to firm level compensation, and show that equilibrium wages do not vary between job types. We find that employment is higher in bonus pay rather than fixed wage jobs. Our contribution, relative to the previous work, is to illustrate the importance of variable pay at the individual level. In particular, our approach explains the variation in compensation form as a function of monitoring costs. In principle, profit sharing plans and stock options are available to all firms, and hence this earlier work cannot explain the observed heterogeneity in compensation form.

Our analysis also suggests a need for more research on the costs of measuring worker performance and worker training, as well as having better measures of compensation form. In future research we need to understand how measurement systems vary across firms, and how the labor market can better provide signals to workers and firms on where they should invest into human capital and job creation. 


\section{REFERENCES}

Azariadis, Costas. 1975. "Implicit Contracts and Underemployment Equilibria." Journal of Political Economy, 83: 11831202.

Azfar, Omar, and Stephan Danninger. 2001. "Profit-Sharing, Employment Stability, and Wage Growth." Industrial and Labor Relations Review, 54(3): pp. 619-630.

Baily, Martin N. 1974. "Wages and Employment under Uncertain Demand." Review of Economic Studies, 41: 37-50.

Beaudry, Paul, and John DiNardo. 1991. "The Effect of Implicit Contracts on the Movement of Wages over the Business Cycle: Evidence from Micro Data." Journal of Political Economy, 99(4): 665-688.

Becker, Gary. 1962. "Investment in $\mathrm{Hu}-$ man Capital: A Theoretical Analysis." Journal of Political Economy, 70: 9-49.

Card, David. 1986. "Efficient Contracts with Costly Adjustment: Short-Run Employment Determination for Airline Mechanics." American Economic Review, 76(5): 1045-1071.

Carmichael, H. Lorne, and W. Bentley MacLeod. 2003. "Caring About Sunk Costs: A Behavioral Solution to HoldUp Problems with Small Stakes." Journal of Law, Economics and Organization, 19(1): 106-118.

Clark, Andrew E. 2003. "Unemployment as a Social Norm: Psychological Evidence from Panel Data." Journal of Labor Economics, 21(2): 323-51.

Fuller, L. L., and William R., Jr. Perdue. 1936. "The Reliance Interest in Contract Damages: 1." The Yale Law Journal, 46(1): 52-96.

Goldberg, Victor P. 1977. "Competitive Bidding and the Production of Precontract Information." Bell Journal of Economics, 8(1): 250-61.

Hall, Robert E., and Edward P. Lazear. 1984. "The Excess Sensitivity of Layoffs and Quits to Demand." Journal of Labor Economics, 2(2): 233-257.

Hart, Oliver D. 1983. "Optimal Labour Contracts under Asymmetric Information:
An Introduction." Review of Economics Studies, 50(1): 3-35.

Hart, Oliver D., and John Moore. 1988. "Incomplete Contracts and Renegotiation." Econometrica, 56(4): 755-785.

Kanemoto, Yoshi, and W. Bentley MacLeod. 1992. "The Ratchet Effect and the Market for Second Hand Workers." Journal of Labor Economics, 10: 85-92.

Lemieux, Thomas, W. Bentley MacLeod, and Daniel Parent. 2009. "Performance Pay and Wage Inequality." Quarterly Journal of Economics, 124(1): 1-49.

MacLeod, W. Bentley, and Daniel Parent. 1999. "Job Characteristics and the Form of Compensation." Research in Labor Economics, 18: 177-242.

MacLeod, W. Bentley, and James M. Malcomson. 1993. "Investments, Holdup, and the Form of Market Contracts." American Economic Review, 83(4): 811-837.

Malcomson, James M, and Frans Spinnewyn. 1988. "The Multiperiod Principal Agent Problem." Review of Economic Studies, 55(3): 391-407.

Mincer, Jacob. 1962. "On-the-job Training: Cost, Returns and Some Implications." Journal of Political Economy, 70(5): 50-79.

Oyer, Paul, and Scott Schaefer. 2005. "Why do some firms give stock options to all employees?: An empirical examination of alternative theories." Journal Of Financial Economics, 76(1): 99-133.

Rosen, Sherwin. 1985. "Implicit Contracts: A Survey." Journal of Economic Literature, 23(3): 1144-75.

Sullivan, Daniel, and Till von Wachter. 2009. "Job Displacement And Mortality: An Analysis Using Administrative Data." Quarterly Journal Of Economics, 124(3): 1265-1306.

Weitzman, M. L. 1983. "Some Macroeconomic Implications of Alternative Compensation Systems." Economic Journal, 93(372): 763-783. 